\title{
Stress Analysis of Steel Plate Girders Subjected to Patch Loading in Elastoplastic Domain
}

\author{
Dragana TURNIĆ*, Nenad MARKOVIĆ, Tomislav IGIĆ
}

\begin{abstract}
This paper considers the stress analysis of steel I girders subjected to patch loading for different lengths of load. Behavior of the girders under the patch loading or uniformly distributed load on the flange and in the plane of web represents complex stability and elastic-plastic problem. The geometric and material non-linearities that exist, also affect the behavior of the girder. A better knowledge of girder behavior is important in order to achieve a more economical and a safer design. In addition to the limit load analysis, the stress analysis is of particular interest. The results from the experiment were used and were compared with the results obtained by modeling the girders in the ANSYS software.
\end{abstract}

Keywords: elastic-plasticity; limit load analysis; patch loading; steel plate girders; stress analysis

\section{INTRODUCTION}

The behavior of welded plate girders subjected to patch load or partially distributed load on the flange in the plane of a web (see Fig. 1) represents a complex stability and elastic-plastic problem. Numerous researches during past decades in this field indicate the main parameters that influence the behavior of plate girder subjected to patch loading: thickness of the web, size of the flange, distance of vertical stiffeners, distance of the longitudinal stiffeners from the upper flange of the girder, yield stresses of the parts of the girder, distribution length of the subjected load, value of the bending moment etc. Both geometric and material non-linearities appear and they influence the behavior of the girder. This paper represents a continuation of the research presented in [1].

The research conducted in this paper is related to the stress state analysis of plate girders, which was not considered in the previous paper. In further text, we will briefly describe the problems and basic elements of our research.

The experimental results by N. Marković are taken as the basis for solving these problems [2].

Girder analysis in computer program ANSYS was done in accordance with the experimental model [3]. The girders were set with the same initial geometrical imperfections of the web as those on the experimental model. Within the numerical analysis, six different material models with different $\sigma-\varepsilon$ curves were considered. In accordance with the standards EN 1993-1-5 [4] numerical modeling of these girder models was performed.

Girder behavior in a nonlinear area is observed, especially in terms of stress state analysis until the ultimate strength is reached, with buckling in the zone where loading is applied.

Also, the cases of stress state occurring in the girders with and without longitudinal stiffening and the cases when the length of loading is $5.0 \mathrm{~cm}$ or $15.0 \mathrm{~cm}$ were analyzed.

Geometrical imperfections of the girders are taken into consideration.

We compared the stress analysis based on the experimental model and the stress analysis obtained by computer modeling of the same model of the girder.

Because of the complexity of this problem, which involves the spatial system, the problem of stability, i.e. the buckling of the web, the appearance of plastic zones before the appearance of buckling and long before the collapse of the girder, a complete theoretical solution does not yet exist.

\section{EXPERIMENTAL MODEL}

Data from the experimental research of Dr. Nenad Markovic were used in the research [2]. These data were used to compare with the data obtained in the software program.

Four cases of girders with the same span $(s=50 \mathrm{~cm})$ and the same height $(h=50 \mathrm{~cm})$ were treated. Two types of girders have longitudinal stiffeners and the other two types of girders do not have a longitudinal stiffener. The application of the load was to the upper flange along the entire width. The load application length is $5.0 \mathrm{~cm}$ for two types of girders, and $15.0 \mathrm{~cm}$ for the other two types of girders. The considered girder of series "A" is presented in Fig. 1 with characteristic notations and the dimensions are shown in Tab. 1.

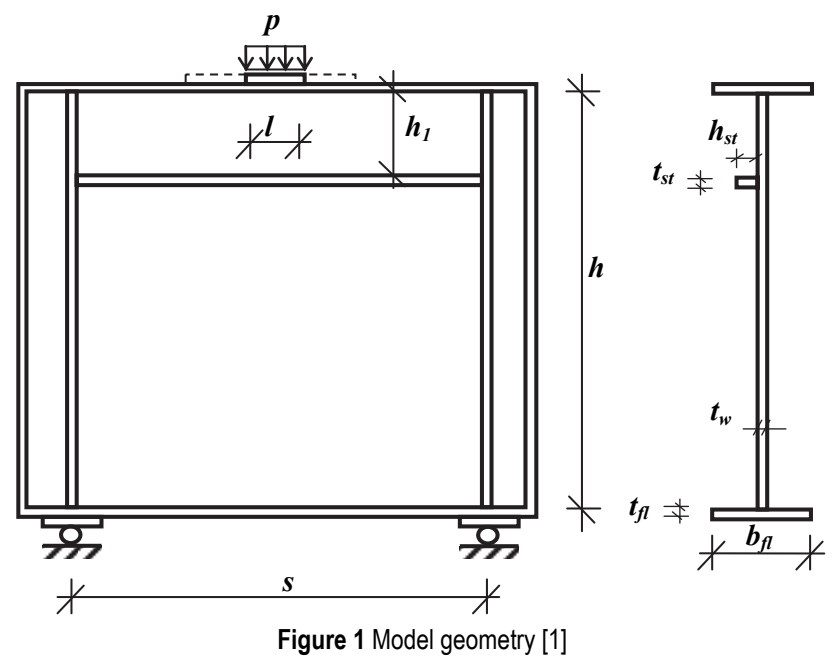

Table 1 Girder model-geometrical characteristics [1]

\begin{tabular}{|c|c|c|c|c|c|c|c|c|c|}
\hline \multirow{2}{*}{ Girder } & $s$ & $h$ & $t_{w}$ & $b_{f l}$ & $t_{f l}$ & $l$ & $h_{s t}$ & $t_{s t}$ & $h_{1}$ \\
\cline { 2 - 11 } & $\mathrm{cm}$ & $\mathrm{cm}$ & $\mathrm{cm}$ & $\mathrm{cm}$ & $\mathrm{cm}$ & $\mathrm{cm}$ & $\mathrm{cm}$ & $\mathrm{cm}$ & $\mathrm{cm}$ \\
\hline $\mathrm{A}_{1}$ & 50.0 & 50.0 & 0.4 & 12.0 & 0.8 & 5.0 & 0 & 0 & 0 \\
\hline $\mathrm{A}_{2}$ & 50.0 & 50.0 & 0.4 & 12.0 & 0.8 & 15.0 & 0 & 0 & 0 \\
\hline $\mathrm{A}_{3}$ & 50.0 & 50.0 & 0.4 & 12.0 & 0.8 & 5.0 & 3.0 & 0.8 & 10.0 \\
\hline $\mathrm{A}_{7}$ & 50.0 & 50.0 & 0.4 & 12.0 & 0.8 & 15.0 & 3.0 & 0.8 & 10.0 \\
\hline
\end{tabular}


A closed frame was designed for the purposes of the experiment. A hydraulic press was used to apply the load step by step. The cessation of the load increase was performed with the achievement of the ultimate load, but the increase of deformations is caused without further increase of the load. During this process, a visible buckling of a part of the upper zone of the vertical web appeared (see Fig. 2).

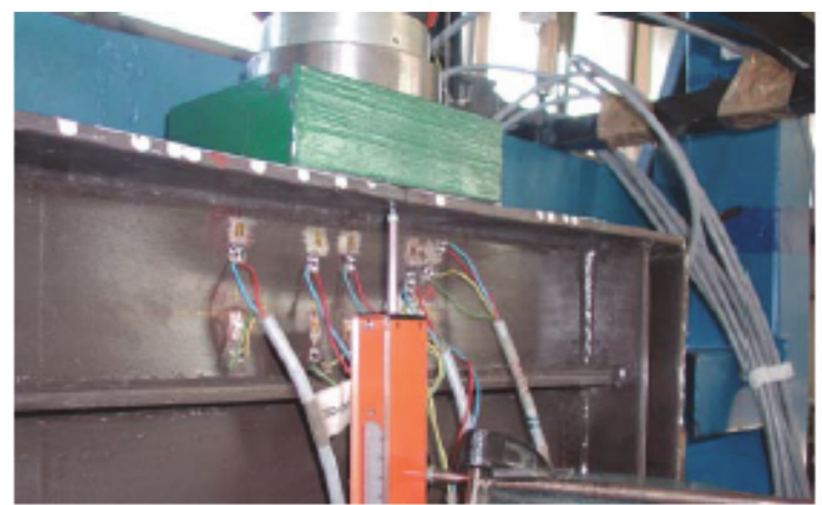

Figure 2 Local buckling of girder-residual deformation [2]

The strains were measured with Hottinger strain gauges (LY11 3/120) on the web below the loaded flange as well as on this flange. Strain gauges were placed as individual vertical gauges and $0^{\circ}-45^{\circ}-90^{\circ}$ rosettes made from individual strain gauges or as ready-made rosettes (see Fig. 15 to Fig. 17). One pair of the strain gauges was placed on each side of the web and also on the loaded flange to enable getting information about the stress through the thickness of web or flange of the girder. The locations of the strain gauges provided an opportunity to cover different cases in terms of lengths of the load and have to take into account the position of the longitudinal stiffeners.

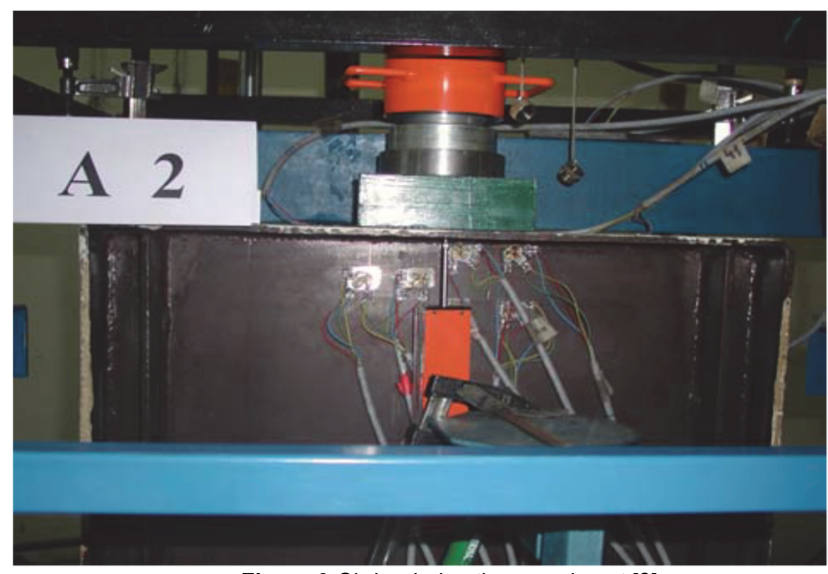

Figure 3 Girder during the experiment [2]

Shear strains were calculated from the measured strains at the points where the strain gauge rosettes were placed. The position of the strain gauges was on both sides of the web or loaded flange. This allows calculating membrane stresses and bending stresses. Normal stresses in the horizontal (longitudinal direction) $\sigma_{x}$, vertical (transversal) direction $\sigma_{z}$ and shear stresses were calculated. On the basis of these values, the main stresses $\sigma_{1}$ and $\sigma_{2}$ and their directions were determined.
Material characteristics were tested and the calculated results were used for creation on nonlinear material models. The steel coupons taken from the webs of the girders which did not sustain permanent deformation were examined by N. Marković. The testing was performed in the Innovation center of the Faculty of Technology and Metallurgy of Belgrade in 2013 in order to determine mechanical properties of steel sheets according to the SRPS EN ISO 6892-1:2012 standard.

\section{NUMERICAL MODELING OF GIRDERS AND FORMATION OF MATERIAL MODELS WITHIN THE NONLINEAR ANALYSIS}

In order to obtain the most accurate results, girder modeling was fully adapted to the experimental models. Numerical modeling was calculated in computer program ANSYS [3].

The girder modeling included: setting of material characteristics, setting the adequate geometry of the girder, the geometric imperfections of the ribs were also entered, setting boundary conditions, setting of loads according to the experimental models, selection of appropriate finite element mesh size, setting other parameters relevant to the analysis.

Numerical models are designed to best describe experimental models.

In a numerical analysis, it is of great importance to set the appropriate material behavior parameters in a proper way. Material imperfections of the girder are in most cases related to errors during fabrication and to other reasons. It can be said that material imperfections, in fact, occur, due to the residual stresses in the material, so they must be calculated in the initial state of the girder.

Based on the data from laboratory tests the $\sigma-\varepsilon$, diagram in Fig. 4 is obtained. The diagram corresponds to one of the coupons.

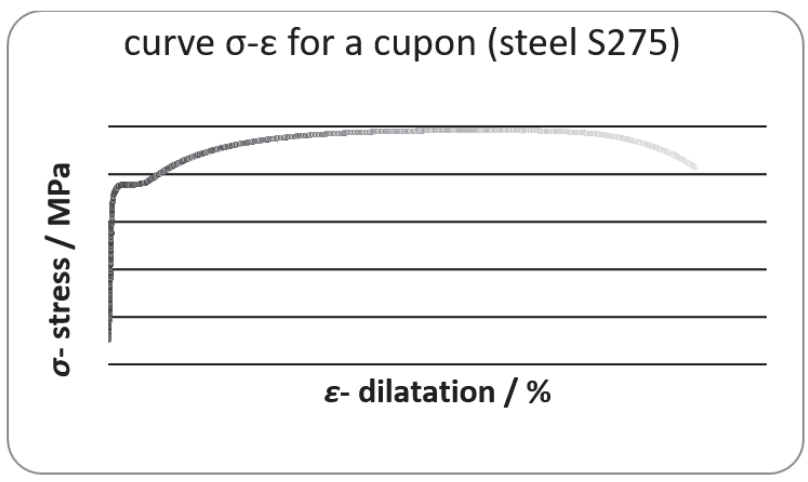

Figure 4 Curve $\sigma-\varepsilon$ obtained by testing

The approximation at a certain number of points was performed to obtain the curve $\sigma-\varepsilon$ (see Fig. 4). The values are increased to $\sigma_{\text {true }}=\sigma(1+\varepsilon), \varepsilon_{\text {true }}=\ln (1+\varepsilon)$ in accordance with the Eurocode 4, EN1993-1-5. The given multilinear curve is displayed in Fig. 5. and obtained values are $f_{y}=329.97 \mathrm{MPa}$ and $f_{u}=449.6 \mathrm{MPa}$ used for all models [8].

These test results were used for getting simplified $\sigma-\varepsilon$ curves. Bilinear curves with tangent modulus $E_{t}=E / 10000$, $E_{t}=E / 1000$ in accordance with the European regulation 
EN1993-1-5 [5] as well as $E_{t}=E / 100$ for the additional analysis were used.

Curve $\sigma-\varepsilon$ (multilinear) which corresponds to the real curve of material

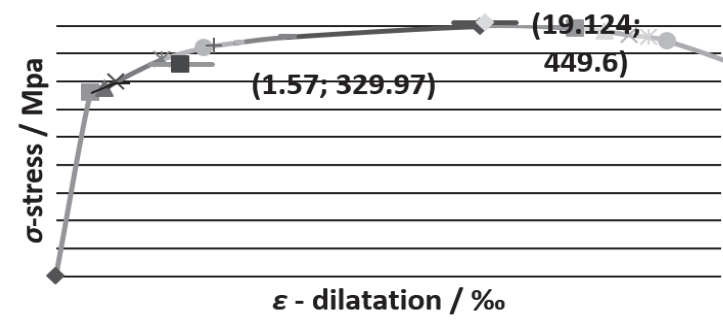

Figure 5 Multilinear curve $\sigma-\varepsilon$ according to curve $\sigma-\varepsilon$ obtained by testing presented in Fig. 4

In addition, we used a multi-linear curve recommended by BSK07 (Swedish regulations) [6]. The modulus of elasticity of material is $E=210 \mathrm{MPa}$ and the Poisson's coefficient is $v=0.3$. Based on von-Mises condition in the frame of the theory of plasticity we use material models on the isotropic rule (for more information, see [1]).

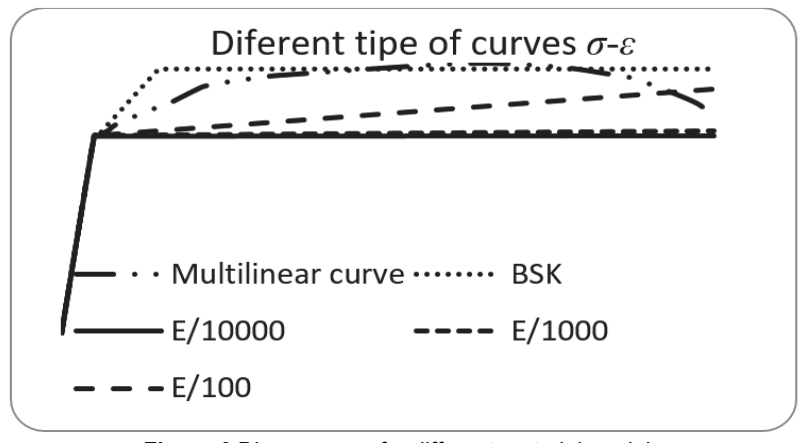

Figure 6 Diagrams $\sigma-\varepsilon$ for different material models

Geometry of the girder was assigned according to the experimental models. The initial geometrical imperfections of the model, measured in the experiment, were designed on the girder web. Imperfections were previously measured during the experiment. The flanges and stiffeners were designed without imperfections.

The loading was applied to the girder in the same manner as in the experiment.

The load was applied in six steps. With each of the different types of girders, the load increment differed, regarding the expected value of ultimate load in accordance with the experimental data. In this way it is possible to monitor the flow of variation of stress and strain state in the girder.

Starting from the size of the finite element mesh, we chose a certain element size. As these elements were made smaller and smaller, as the mesh was refined, the computed solution would approach the true solution. Our criterion was to achieve a difference between two iterations less than $5 \%$. In that way, we perform discretization of the mesh of the finite element. The adopted size of the finite element was $1.5 \mathrm{~cm}$. The finite elements of the type "SOLID 186" were defined by twenty nodes. It was very convenient for nonlinear analysis [3].

\section{STRESS STATE VARIATION UNTIL GIRDER ULTIMATE LOAD CAPACITY IS REACHED}

The problem of local buckling is very complex [7]. During loading of the girder, still in the elastic zone, the first to occur are the deformations on the lower part of the web under the longitudinal stiffening. With the further increase of the force, the deformation on the upper part of the web between the loaded flange and longitudinal stiffening continues. Such a combination of stresses is formed that the plasticity condition is reached. Approaching to the ultimate load, buckling in the upper part of the web becomes more prominent, only to become dominant when the ultimate load capacity is reached. After that, with small force increased increments, this buckling increases uncontrollably and the girder fails in that zone. After unloading of the girder, residual plastic deformations remain, which are more prominent in the upper part of the web.

We consider that the ultimate load capacity is reached when the solution starts to diverge. In this case, sudden deformations occur on the girder and the girder loses stability.

The value of the force at which the girder loses stability is taken as the ultimate load capacity. For the obtained value of the ultimate load, the stress reaches the maximum value and then abruptly declines [8].

In Fig. 7 we can see a diagram of increasing force and von Mises stresses for $A_{1}$ up to the ultimate load. The tensile strength of material is $f_{u}=449.6 \mathrm{MPa}$. In the same figure we can see that already from the load of $92.96 \mathrm{kN}$ at certain points the yielding stresses are reached $\left(f_{y}=329.97\right.$ $\mathrm{MPa})$. The highest value of von Mises stress is 440.59 $\mathrm{MPa}$.

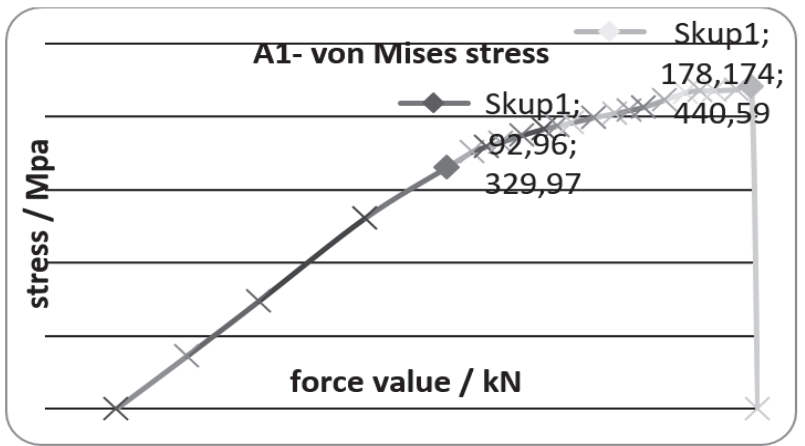

Figure $7 \mathrm{~A}_{1}$ girder-von-Mises stress depending on the load

In Fig. 8 we can see von-Mises stresses for type of $A_{1}$ girder.

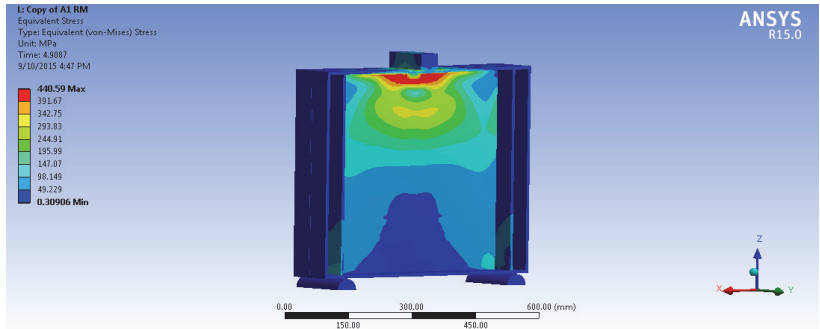

Figure 8 The state of stresses for girder $A_{1}$. Ultimate load is $178,174 \mathrm{kN}$ [1]

The remaining cases are treated similarly. Stress state for the $A_{2}$ girder is presented in Fig. 9 and Fig. 10. At the 
force of $131.9 \mathrm{kN}$ (60.8 \% of ultimate load) yielding stress is reached at certain points, and the highest value of vonMises stress of $446.65 \mathrm{MPa}$ (tensile strength $f_{u}=449.6$ $\mathrm{MPa}$ ), is reached at the ultimate load of $216.92 \mathrm{kN}$ (see Fig. 9).

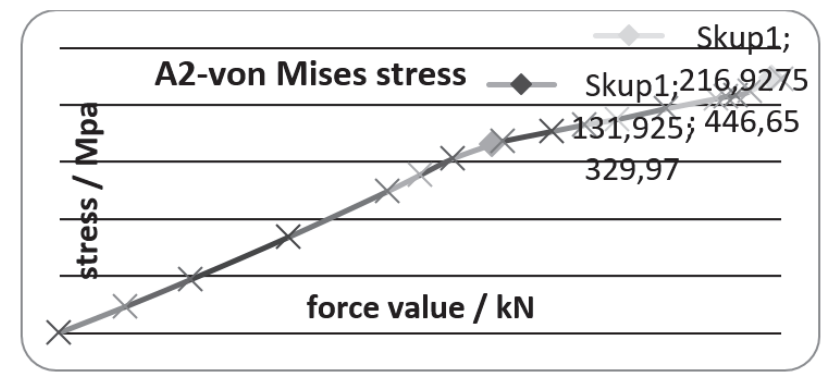

Figure $9 A_{2}$ girder-von-Mises stress depending on the load

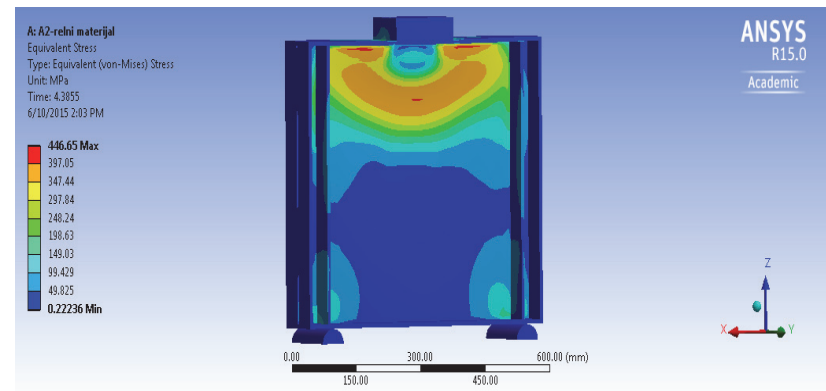

Figure 10 The state of stress for girder $A_{2}$. Ultimate load is $216,9275 \mathrm{kN}$

As in the previous cases, for the girder $A_{3}$, after reaching the ultimate load $(188.5 \mathrm{kN})$ the stress value is the highest and amounts to $436.98 \mathrm{MPa}$ (tensile strength $f_{u}=$ $449.6 \mathrm{MPa})$, and for the load of $95.697 \mathrm{kN}(50.77 \%$ of the limit value) the yield stress is reached in certain points (see Fig. 11 and Fig. 12).

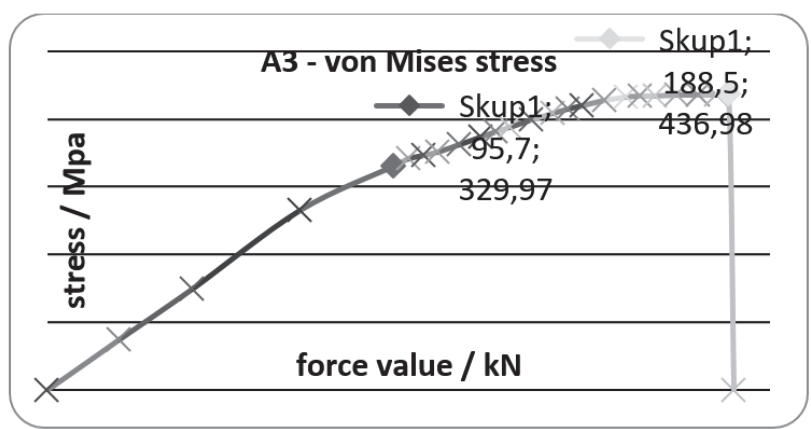

Figure $11 A_{3}$ girder-von-Mises stress depending on the load

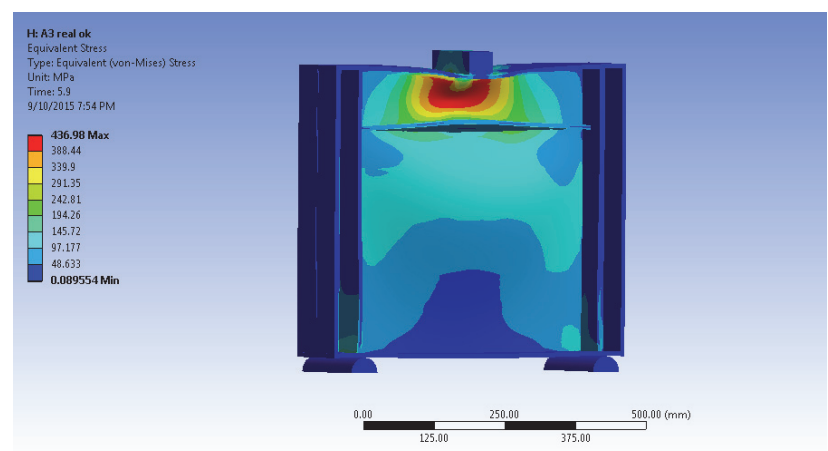

Figure 12 The state of stresses for girder $A_{3}$. Ultimate load is $188.5 \mathrm{kN}$
In Fig. 12 is presented the status of von-Mises stresses for the ultimate load value of $188.5 \mathrm{kN}$.

The $\mathrm{A}_{7}$ girder achieves plastic phase in certain points at the load value of $192.86 \mathrm{kN}$ when yield stress is reached, which is $70.39 \%$ of the limit load value. After reaching the limit load of $274 \mathrm{kN}$, the corresponding stress value is 425.41 MPa.

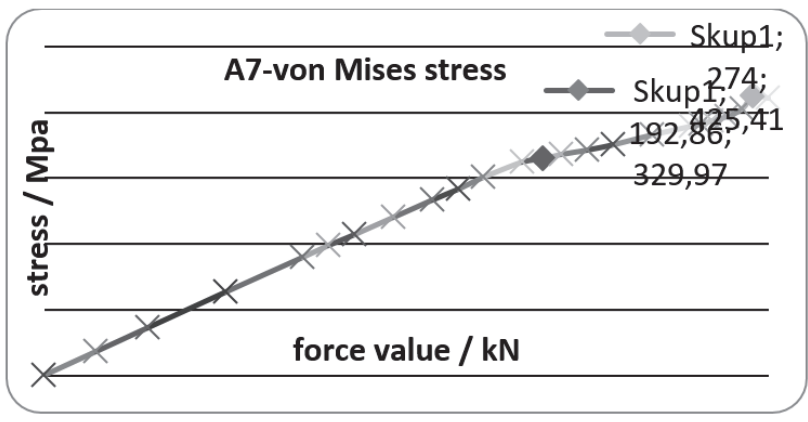

Figure $13 \mathrm{~A}_{7}$ girder-von-Mises stress depending on the load

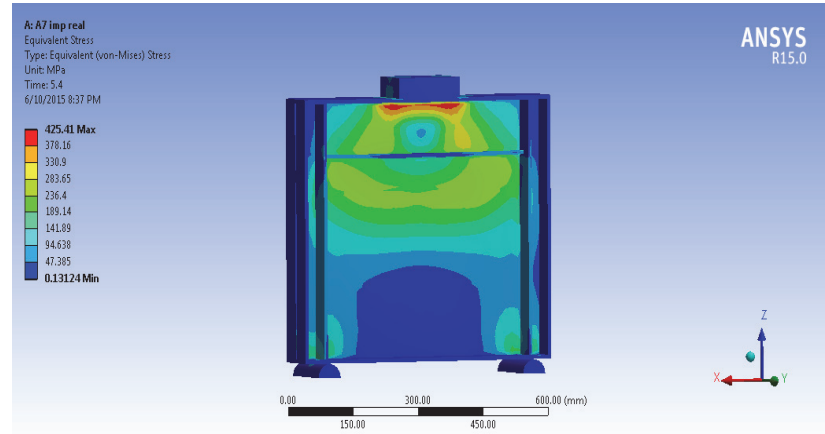

Figure 14 The state of stresses for girder $A_{7}$. Ultimate load is $274 \mathrm{kN}$

\section{STRESSES IN CHARACTERISTIC POINTS AND COMPARISON TO THE EXPERIMENTAL RESULTS}

Characteristic locations of the strain gauges applied to girder webs (all type of girders), which are experimentally tested are presented in Fig. 15, Fig. 16 and Fig. 17. Dimensions are in $\mathrm{cm}$.

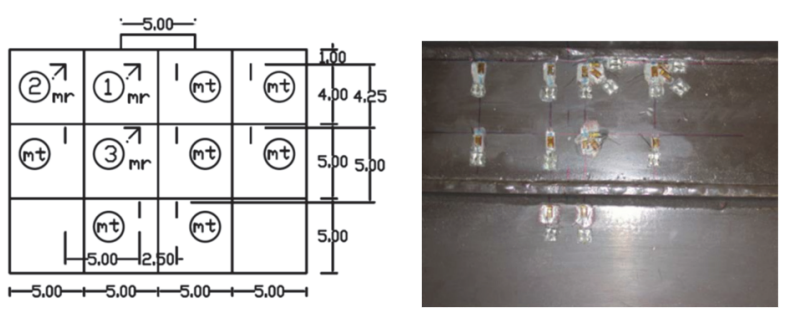

Figure 15 Position of the strain gauges on the web of the girders $A_{1}$ (without longitudinal stiffening) and $A_{3}$ (with longitudinal stiffening) (front and rear side) [2]
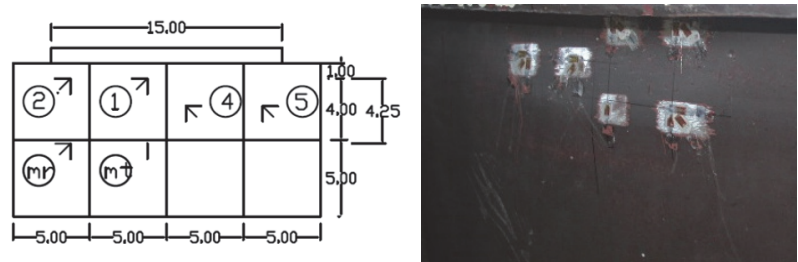

Figure 16 Position of the strain gauges on the web of the girder $A_{2}$ (front and rear side) [2] 

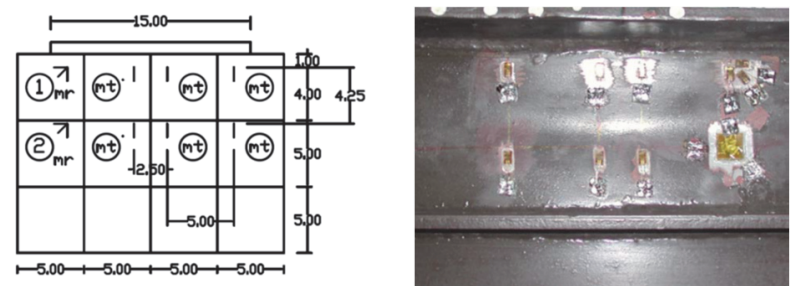

Figure 17 Position of the strain gauges on the web of the girder $A_{7}$ (front and rear side) [2]

For each of the girders, stress diagrams in characteristic points are determined. In that process, the ultimate load values and stress and strain diagrams of each of four cases of girders are determined for six material models: multi-linear curve which is obtained after the curve obtained by the testing (see Fig. 5) and according to the recommendations in EN1993-1-5, multi-linear curve according to the recommendations in Swedish regulations BSK07 [6], bilinear curve with tangent modulus $E_{t}=$ $E / 10000$ (according to the recommendations in EN1993-15), bilinear curve with $E_{t}=E / 1000$ for additional research, bilinear curve with tangent modulus $E_{t}=E / 100$ (according to the recommendations in EN1993-1-5 [5]), see Fig. 6. The obtained results in numerical simulations of the girder model are compared to the results of the corresponding models from the experiment.

In the following diagrams are presented the $\sigma_{x}$ and $\sigma_{z}$ stress values in characteristic points in which the strain gauges were placed, at the front side of web, during the experiment. What is presented, are the stresses for the $A_{3}$ girder for different material models (see Fig. 18).
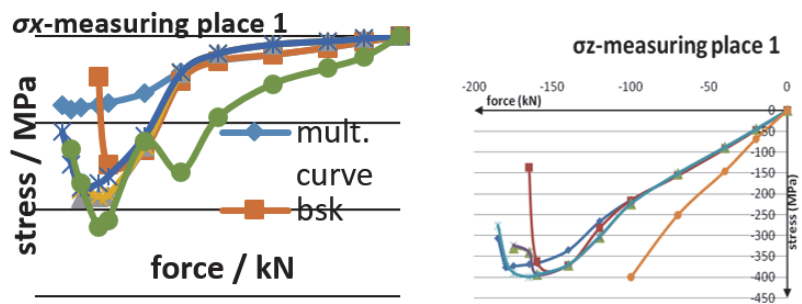

a) Stress values $\sigma_{x}$ and $\sigma_{z}$ at the measuring place 1 ox-measuring place 2
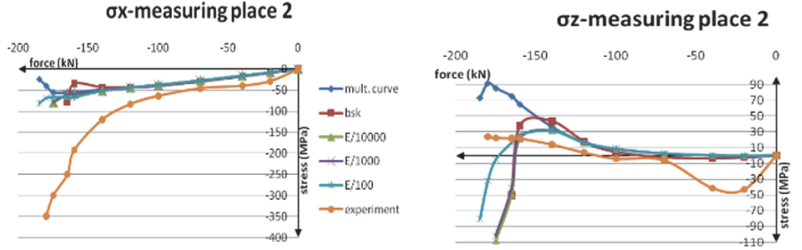

b) Stress values $\sigma_{x}$ and $\sigma_{z}$ at the measuring place 2
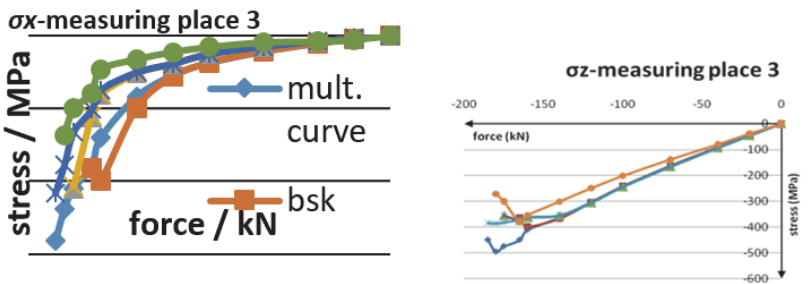

c) Stress values $\sigma_{x}$ and $\sigma_{z}$ at the measuring place 3

Figure $18 \mathrm{a}$ ), b) i c) Stress values $\sigma_{x}$ and $\sigma_{z}$ at the measuring places 1, 2 and 3 (see Fig. 15) for girder $A_{3}$ different material models

The analysis of the obtained data on the diagrams exhibits satisfactory agreement of stress values for various modes of material behavior, in terms of stress monitoring.
In addition to the material imperfections, geometrical imperfections of the girders are taken into consideration. For the models the stress values are calculated and compared to the stresses calculated in the experiment. The values of the stress in the experiment are obtained by calculation based on the values of measured strains, using a generalized Hook's law.

For the $A_{1}$ girder, the results are compared. The ultimate load for the girder with imperfections is 178.174 $\mathrm{kN}$, and the value of the ultimate load in the experiment is $165 \mathrm{kN}$. The obtained stress values on the appropriate measuring places are presented in Fig. 19.
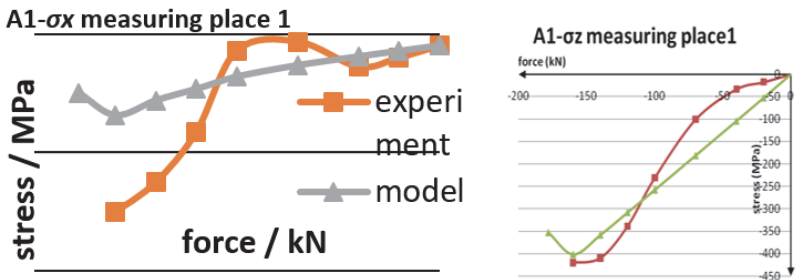

a) Stress values $\sigma_{x}$ and $\sigma_{z}$ at the measuring place 1
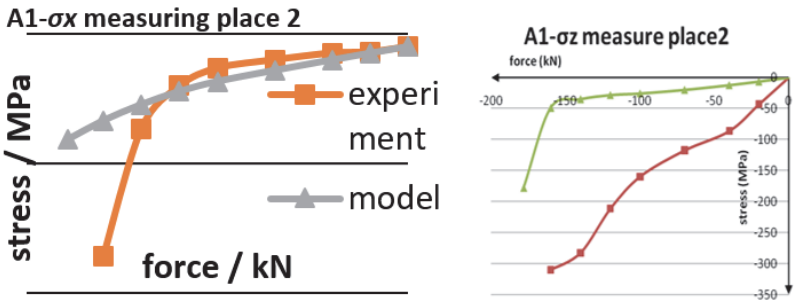

b) Stress values $\sigma_{x}$ and $\sigma_{z}$ at the measuring place 2
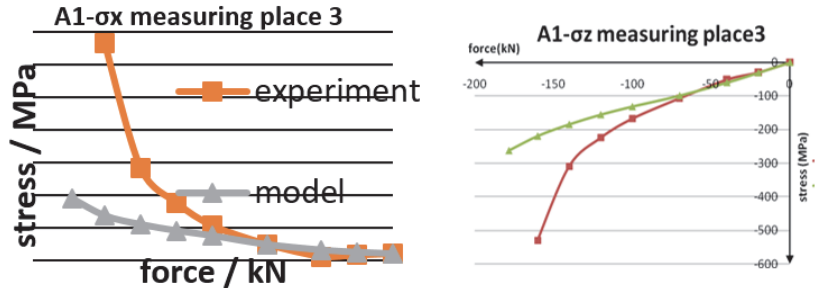

c) Stress values $\sigma_{x}$ and $\sigma_{z}$ at the measuring place 3

Figure $19 \mathrm{a}), \mathrm{b}), \mathrm{c}$ ) Stress values $\sigma_{x}$ and $\sigma_{z}$ at the measuring places front side (see Fig. 15) for girder $A_{1}$

Stress values $\sigma_{x}$ and $\sigma_{z}$, for the girder $A_{2}$ at certain measuring places (see Fig. 16) are presented in Fig. 20. The ultimate load capacity for the $A_{2}$ girder is $215 \mathrm{kN}$ according to the experiment, and $216.9275 \mathrm{kN}$ via the numerical simulation.

For the $A_{3}$ girder the stress values $\sigma_{x}$ and $\sigma_{z}$ are presented also with the increase of forces (see Fig. 21). The ultimate load capacity during numerical simulation for the girder with geometrical imperfections is $188.5 \mathrm{kN}$ and in the experiment it is $183 \mathrm{kN}$. The stress values exceeding tensile strength values need not be taken into consideration $\left(f_{u}=449.6 \mathrm{MPa}\right)$.

In Fig. 22 are presented the stress diagrams $\sigma_{x}$ and $\sigma_{z}$ for the girder $A_{7}$ and measuring place 1. The ultimate load capacity for the girder with geometrical imperfections is $274 \mathrm{kN}$. In the experiment the ultimate load obtained is 255 $\mathrm{kN}$. 

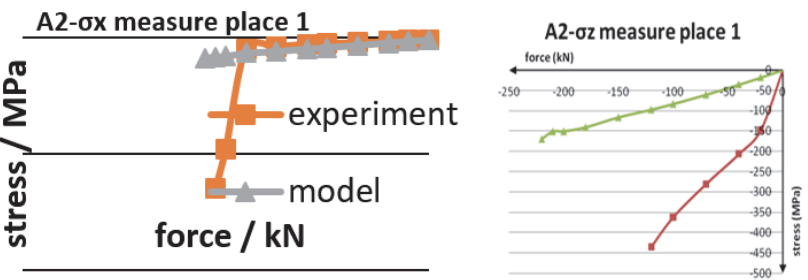

a) Stress values $\sigma_{x}$ and $\sigma_{z}$ at the measuring place 1
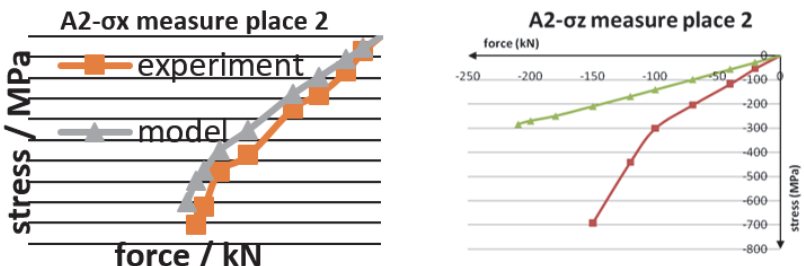

b) Stress values $\sigma_{x}$ and $\sigma_{z}$ at the measuring place 2
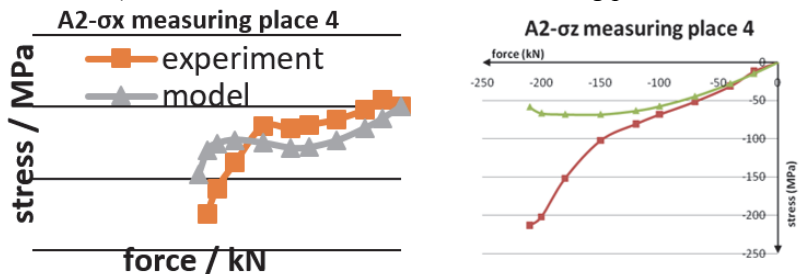

c) Stress values $\sigma_{x}$ and $\sigma_{z}$ at the measuring place 4
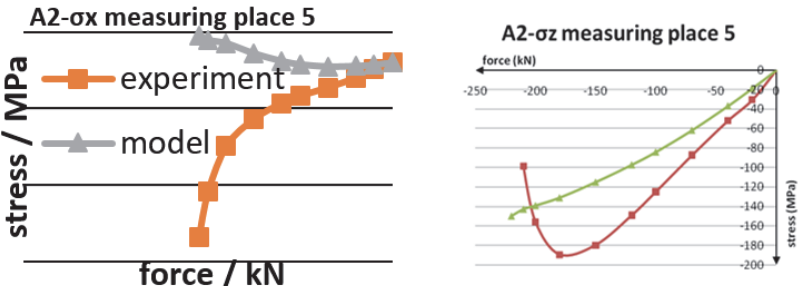

d) Stress values $\sigma_{x}$ and $\sigma_{z}$ at the measuring place 5

Figure $20 \mathrm{a}$ ), b), c), d) Stress values $\sigma_{x}$ and $\sigma_{z}$ at the measuring places front side (see Fig. 16) for girder $A_{2}$
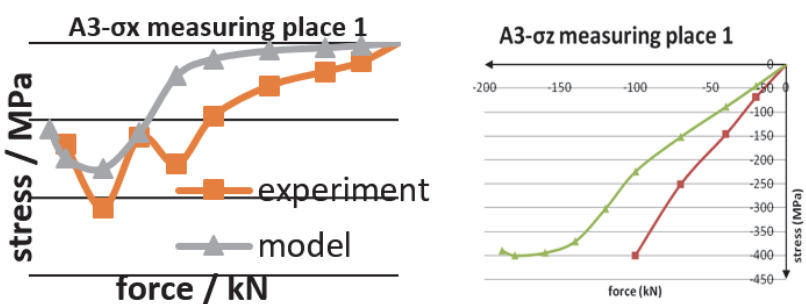

a) Stress values $\sigma_{x}$ and $\sigma_{z}$ at the measuring place 1
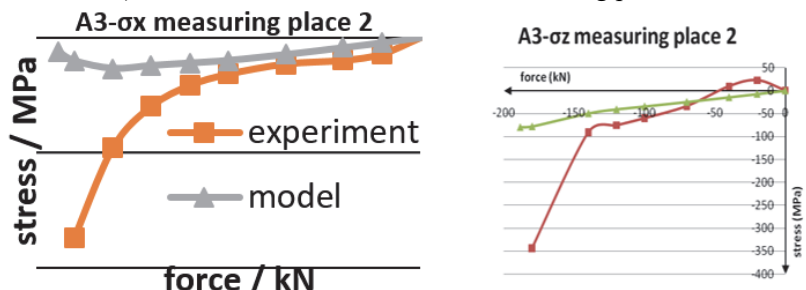

b) Stress values $\sigma_{x}$ and $\sigma_{z}$ at the measuring place 2
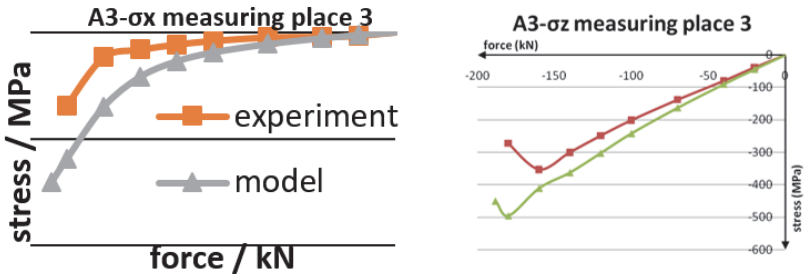

c) Stress values $\sigma_{x}$ and $\sigma_{z}$ at the measuring place 3

Figure $21 \mathrm{a}$ ), b), c) Stress values $\sigma_{x}$ and $\sigma_{z}$ at the measuring places front side (see Fig. 15) for girder $A_{3}$
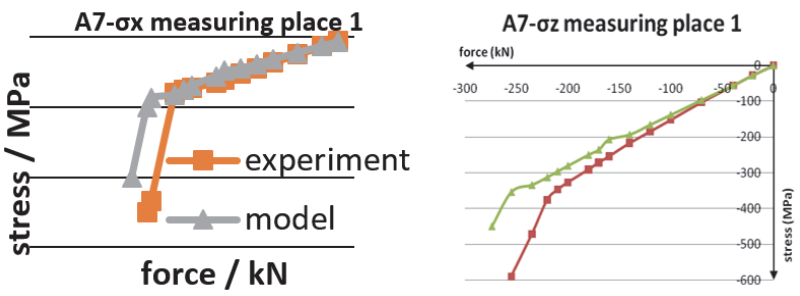

Figure 22 Stress values $\sigma_{x}$ and $\sigma_{z}$ at the measuring place 1 front side (see Fig. 17) for girder $A_{7}$

An analysis of the obtained results of stress values revealed certain deviations in the values obtained experimentally and through numerical simulation. Within the numerical models, for the reasons of modeling simplification, the following were ignored: impacts of imperfections of flanges and stiffening, impacts of welds between the flanges and webs and stiffeners and webs; mean values of yield stress $f_{y}$ and tensile strength $f_{u}$ are considered, etc. It is assumed that taking of those initial geometrical imperfections does not produce considerably better results, so they can be ignored in this case in the numerical modeling. The following must be emphasized: during numerical simulations of the model, the form, character and flow of deformation development and buckling are identical as in the experiment, and for each sample with which the comparison was made, too, which is presented in the paper [1].

Also, a better agreement of the stress values of the girders with longitudinal stiffeners, $A_{3}$ and $A_{7}$ is observed.

\section{CONCLUSION}

The assessment of the measured strains used for obtaining the stress state, along with other results of undertaken measuring confirmed that the behavior of the girder web exposed to patch loading represents a complex problem of stability in an elastic-plastic zone, with early development of plasticizing.

During the nonlinear numerical simulation of the experiments, the stresses in the characteristic points for all cases of girders are calculated, at the places where strain gauges were placed in the previously described experiment (see Fig. 15, Fig. 16 and Fig. 17). Strain gauges were placed on the front and back side of the girder web, and on the basis of the obtained strain values the stress values in $x$ and $z$ directions are calculated.

It is determined, that in the zone where the load was applied the yield stresses on the web were reached before the ultimate load, without a notable deformation in that zone of the web.

By analyzing the obtained data, it is found that the onset of plasticization occurs at $58.5 \%$ of the ultimate load. This is the average value for all types of the girders.

The deformations which occur in this case do not need to be considerable. This provided data on the plastic reserve possessed by the girder.

This suggests that for every structure, two combinations need to be analyzed:

1) Girder made of high-grade steel, with higher-yield strength and with a slender web.

2) Girder made of lower-grade steel, with a thick web. 
The presented MKE analyses in numerical simulation provide finding a cost-efficient design with a high reliability.

The stress values are compared for different material models, for individual measuring points, and within each of those diagrams, for the sake of analysis there is one diagram which corresponds to the experimental results and it is designated as "experiment". The stresses exceeding the value of tensile strength $\left(f_{u}=449.6 \mathrm{MPa}\right)$ are not presented in the diagrams.

Due to their complexity and non-existing comprehensive solutions, the problem of patch loading is not a closed book. It is topical, as attested by increasing number of papers, doctoral dissertations, changes of European codes and propositions for their amendments [911].

From the previous statements, it is concluded that there is a satisfactory agreement of the established numerical models of these researches with experimental models. These researches cannot provide all the answers, but these tests and potential for new tests and different models can contribute to explanation of this complex problem. This provides potential for new testing of behavior of such or different girder models using numerical simulation. The tests which are conducted, in this manner, facilitate performing of girder analyses which would indirectly contribute to adoption of correct approaches to obtaining of theoretical results, for instance, with the aim of analyzing failure mechanisms in a non-elastic zone (see [12-14]).

Also, there is potential for further analysis of many parameters, changes of girder geometry, testing of girders with openings in the web, as well as application of new materials for whole girders or their parts.

\section{Acknowledgement}

This research is conducted at The Faculty of Civil Engineering and Architecture of the University of Niš in the framework of the project in the field of technological development in the period 2011-2019, and titled "Experimental and theoretical research of linear and planar systems with semi-rigid joints from the aspect of second order theory and stability analysis" (TR 36016), financed by the Ministry of Education, Science and Technological development of the Republic of Serbia.

\section{REFERENCES}

[1] Turnić, D., Marković, N., Igić, T., Nikolić, V., \& SpasojevićSurdilović, M. (2017). Analysis of material non-linearity of steel girders subjected to patch loading. Tehnički vjesnik, 24(6), 1991-1998. https://doi.org/10.17559/TV-20160524114854

[2] Marković, N. (2003), Izbočavanje limenih nosača pod dejstvom lokalnog opterećenja, Doktorska disertacija, Građevinski fakultet u Beogradu, (mentori: N. Hajdin i B. Ćorić).

[3] ANSYS 15, LS-DYNA Keyword user`s manual, Vol I, II, III, February 2013, Version R7.0, Livermore Software Technology Corporation.

[4] Commentary and worked examples to EN 1993-1-5. (2007). Plated structural elements, JRT Scientific and Technical Reports, B. Johansson, R. Maquoi, G. Sedlacek, C. Müller, D. Beg.
[5] EN 1993-1-5: 2006 Eurocode 3: Design of steel structures, Part 1-3: Plated structural elements, November 2006, ISBN 0580496678.

[6] BSK07, (2007). Boverkets handbok om stålkonstruktioner BSK 07, ISSN: 1400-1012 (in Sweden).

[7] Braun B, (2010). Stability of steel plates under combined loading, Doctoral Thesis, $\mathrm{Nr}$ 2010-3, Institut für Konstruktion und Entwurf Stahl-Holz- und Verbundbau, Universität Stuttgart, Germany.

[8] Turnić, D. (2016). Nelinearno ponašanje i granična nosivost limenih nosača opterećenih lokalizovanim opterećenjem, doktorska disertacija, Građevinsko-arhitektonski fakultet Niš, Srbija.

[9] Kövesdi, B. \& Dunai, L. (2016). Bending, shear and patch loading interaction behavior of slender steel sections. $9^{\text {th }}$ International Conference "Bridges in Danube Basin 2016", $B D B$ 2016. Procedia Engineering, 156, 199-206. https://doi.org/10.1016/j.proeng.2016.08.287

[10] Bo, W, Jia-Li, C., \& Lan, K. (2018). End patch loading behavior and strengthening of locally corroded steel Ibeams. Journal of Constructional Steel Research, 148, 371382. https://doi.org/10.1016/j.jcsr.2018.05.029

[11] Chacón. R., Mirambell, E., \& Real, E. (2010). Hybrid steel plate girders subjected to patch loading, Part 2: Design proposal. Journal of Constructional Steel Research, 66, 709715. https://doi.org/10.1016/j.jcsr.2009.12.004

[12] Mijušković, O. \& Ćorić, B. (2013). Patch loading-analytical approach to critical load determination. Građevinar, 65(1). https://doi.org/10.14256/JCE.750.2012

[13] Loaiza, N., Graciano, C., Chacon, R., \& Casanova, E. (2017). Influence of bearing length on the patch loading resistance of multiple longitudinally stiffened webs. Proceedings of Eurosteel 2017, 1, 4199-4204. https://doi.org/10.1002/cepa.477

[14] Rogač, M., Mijušković, O., Lučić, D., \& Aleksić, S. (2014). Analysis of flange impact on critical patch load of thinwalled I-girders. Građevinar, 66(4), 311-321.

\section{Contact information}

Dragana TURNIĆ, PhD, Assistant Professor (Corresponding author)

Faculty of Civil Engineering and Architecture, University of Niš,

Aleksandra Medvedeva 14, 18000 Niš, Serbia

+381642282598

E-mail: dragana.turnic@gaf.ni.ac.rs

Nenad MARKOVIĆ, PhD

Matice srpske 62/62,

11000 Belgrade, Serbia

E-mail: nenadgm@eunet.rs

Tomislav IGIĆ, PhD, Full Professor

Faculty of Civil Engineering and Architecture,

University of Niš

Aleksandra Medvedeva 14, 18000 Niš, Serbia

+38118588200

E-mail: tomislav.igic@gaf.ni.ac.rs 